Portland State University

PDXScholar

\title{
Spatial and Temporal Patterns of Amphibian Chytrid Fungus Batrachochytrium Dendrobatidis Occupancy in Amphibian Habitats
}

Tara Chestnut

Portland State University

Follow this and additional works at: https://pdxscholar.library.pdx.edu/mem_gradprojects

Part of the Natural Resources and Conservation Commons, and the Natural Resources Management and Policy Commons Let us know how access to this document benefits you.

\section{Recommended Citation}

Chestnut, Tara, "Spatial and Temporal Patterns of Amphibian Chytrid Fungus Batrachochytrium Dendrobatidis Occupancy in Amphibian Habitats" (2013). Environmental Science and Management Professional Master's Project Reports. 1.

https://pdxscholar.library.pdx.edu/mem_gradprojects/1

https://doi.org/10.15760/mem.13

This Project is brought to you for free and open access. It has been accepted for inclusion in Environmental Science and Management Professional Master's Project Reports by an authorized administrator of PDXScholar. Please contact us if we can make this document more accessible: pdxscholar@pdx.edu. 


\section{Spatial and temporal patterns of amphibian chytrid fungus Batrachochytrium dendrobatidis occupancy in amphibian habitats}

\section{Tara Chestnut}

Presentation in partial fulfillment of the degree requirements for Master of Environmental Management

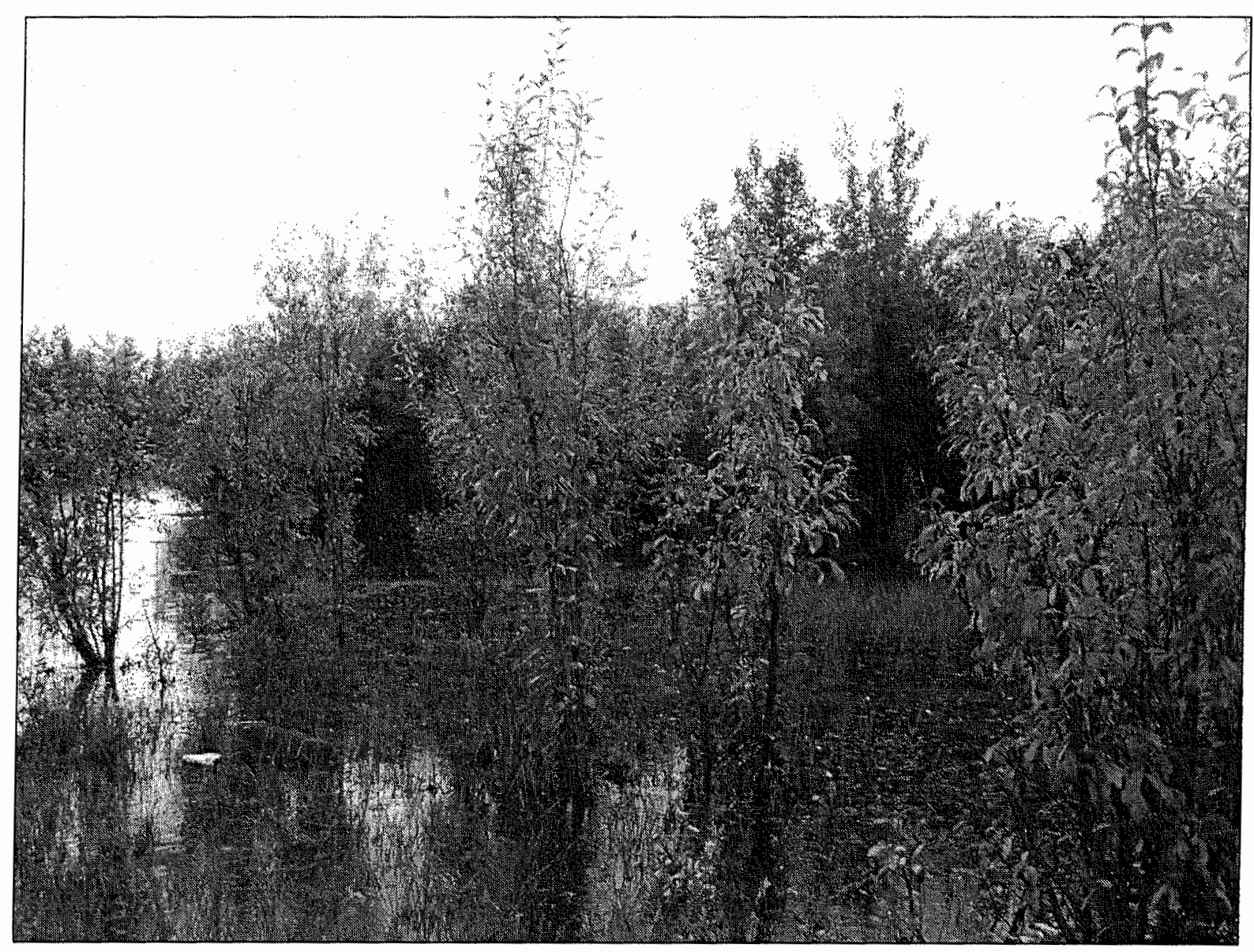

Friday, June 15, $2012 \quad 1: 30-3: 00 \mathrm{pm}$

USGS Oregon Water Science Center, 2130 SW $5^{\text {th }}$ Ave, Willamette Conf. Room

Academic Advisor: Dr. John Rueter

Community Partner: Chauncey Anderson, USGS 
Tara Chestnut |PO Box 1576 | Portland, OR 97207 | 360-357-8758 | tarachestnut@gmail.com

April 17, 2013

Dear Dr. Rueter:

Please accept my report titled "Heterogeneous occupancy of Batrachochytrium dendrobatidls in waters of North America" as final component of the ESM MEM program. I performed this analysis for the US Geological Survey (USGS) under the supervision of Chauncey Anderson, Hydrologist and Team Lead. I am truly grateful for Chauncey's support and enthusiasm for the project.

The USGS is a science organization that provides impartial information on the health of our ecosystems and environment, as well as other valuable services. Their mission is as follows: "The USGS serves the Nation by providing reliable scientific information to describe and understand the Earth; minimize loss of life and property from natural disasters; manage water, biological, energy, and mineral resources; and enhance and protect our quality of life."

My project was completed in support of this mission. This work will inform conservation and provide valuable information to managers concerned with water quality, aquatic ecology, wildlife diseases, and amphibian conservation.

Thank you for your involvement with my academic endeavors and your service to me as an advisor.

Best Regards,

Tara Chestnut 


\section{Title Page}

Heterogeneous occupancy of Batrachochytrium dendrobatidis in waters of North America 
Abstract 


\section{Key Words}

Batrachochytrium dendrobatidis, Chytridiales, North America, disease, pathogen, ecology 


\section{Introduction}

Chytrid fungi are the most ancestral of the fungi and are global in distribution (Hibbett et al. 2007, Adl et al. 2012). There are over 1200 species of Chytridiomycota described from freshwater, marine and terrestrial systems in temperate, tropical and tundra environments (Iblings et al. 2004, James et al. 2006, Gleeson et al. 2007). Chytridiales are characterized by a range of morphologies and share the flask- or pot-like shape of the zoosporangia, within which motile zoospores develop (Barr 2001, Letcher et al. 2005). Chytrids function primarily as plant saprobes and parasites (Shearer et al 2007), but some also parasitize animals (Kagami et al. 2004, Longcore et al. 1999). Chytrids are observed in conjunction with the decline of freshwater and marine algal blooms, they decompose excess pollen, and comprise the fungal flora in gut of herbivores (Trinci et al. 1994, Thorsen 1999, Nicholson et al. 2010). Some chytrids also parasitize micro-invertebrates, insects and amphibians (Longcore et al. 1999, Penalva-Arana et al. 2011, McMahon et al. 2013).

The amphibian chytrid fungus, Batrachochytrium dendrobatidis $(\mathrm{Bd})$ is the only chytrid known to infect a vertebrate host (Longcore et al. 1999). Bd exists free-living in the aquatic environment (Kirshetein et al. 2007, Walker et al. 2007). Lab experiments have demonstrated Bd survival on sterilized moist sand for up to three months and it remained infective in lake water for up to seven weeks (Johnson \& Spear 2004), Bd cultures can be maintained under lab conditions for several months (personal observation), which suggests Bd can survive in the environment without a host as long as nutrients are not limiting. In the aquatic environment, Bd is detected by filtering water samples to capture free-living zoospores and zoosporangia then performing a qPCR analysis (Kirshtien et al. 2007, Walker et al. 2007). Bd has not been reliably isolated 
from sediments (Kirshtein et al. 2007). The goal of our research was to study free-living Bd in amphibian habitats to better understand its ecology and host-pathogen dynamics.

Biodiversity is declining at a global scale, and since 1980 , the extinction rate of amphibians is at least 105 times higher than the expected background rate (McCallum 2012). The causes of global biodiversity loss are not simple or the result of a single action (McCallum 2012, Lawler et al. 2010). Rather, species are declining because of complex interactions and synergistic effects of natural and human induced stressors, which include and are not limited to habitat loss, habitat degradation, invasive species and disease (Butchart et al. 2010). Chytridiomycosis, the disease caused by $\mathrm{Bd}$, is implicated as a causal agent in contemporary global amphibian declines (Rohr et al 2010, Vredenburg et al. 2010). To date, most Bd research efforts have focused on the amphibian-Bd system with little focus on the ecology of Bd independent of the amphibian host (but see Mitchell et al. 2007, Woodhams et al. 2009). Our research sought to describe spatial and temporal patterns of Bd occupancy and density in amphibian habitats, the aquatic environment outside of the amphibian host.

$\mathrm{Bd}$ is associated with mass amphibian mortalities and local extinctions in both disturbed and pristine landscapes in temperate and tropical regions (Lips et al, 2006, Rachowicz et al. 2006, Vredenburg et al. 2009). In infected amphibians, Bd exhibits sensitivity to a number of environmental variables including temperature, elevation, rainfall, and season (Young et al. 2001, Collins et al. 2003, Berger et al. 2004, Drew et al, 2006). It has a wide physiological tolerance for temperature and $\mathrm{pH}$ (Piotrowski et al. 2004), which generally mirrors the thermal and $\mathrm{pH}$ tolerance of many amphibian species (Karns 1992, Wyman \& Jancola 1992). In 
laboratory conditions, Bd can grow and reproduce between 4 and 25 degrees Celsius $(\mathrm{C})$, with ideal temperatures between 17 and 25 degrees C (Piotrowski et al. 2004). Bd does not grow well above 28 degrees $\mathrm{C}$ and survival is reduced above 30 degrees C. Mortality occurs when held at 37 degrees $\mathrm{C}$ for more than 4 hours. The ideal $\mathrm{pH}$ range for $\mathrm{Bd}$ is between 6 and 7, and it can tolerate a range from $\mathrm{pH} 4-10$ (Piotrowski et al. 2004).

Our research focused on describing Bd ecology outside of the amphibian host, which included the seasonal patterns of occupancy and density. Occupancy modeling is a powerful tool to estimate site occupancy and detection probability when detection is imperfect (MacKenzie et al. 2002). These models have been employed to investigate disease ecology in amphibians, fish and birds, where the focus was on pathogen occurrence in the host (Thompson 2007, McClintock et al. 2010). We were interested in applying occupancy models to investigate disease ecology on pathogen occurrence in the host's environment. Our first objective was to determine if Bd exhibits seasonality in detection or density in amphibian habitats. We predicted that $\mathrm{Bd}$ detection and density would follow the same trends observed in amphibians, with the highest detections and densities in the spring and the lowest in the late summer/autumn (Retallick et al. 2004, Pearl et al. 2007, Adams et al. 2010). Our second objective was to determine if there are relationships between $\mathrm{Bd}$ occupancy of amphibian habitats can be explained by variables important to $\mathrm{Bd}$ in amphibians, which included water quality (i.e. temperature, $\mathrm{pH}$, specific conductance), geography (i.e. latitude, longitude, elevation), weather conditions (i.e. precipitation, temperature (min, max, range), dew point), or time (i.e. Julian Day). Our third objective was to determine if the probability of Bd detection in amphibian habitats could be explained by the number of samples taken, sample volume, or water 
quality (i.e. temperature, $\mathrm{pH}$, specific conductance). We predicted that detection probability would increase as the number of samples and volume of water per sample increased, and would increase the closer temperature and $\mathrm{pH}$ were to the ideal range for $\mathrm{Bd}$.

The results of our work will inform disease ecology and amphibian conservation, and the understanding of amphibian exposure to Bd in situ seasonally and over time. Additionally, the results may be applied to risk assessment, aid in policy development, and inform regulatory decision-making processes.

\section{Materials and Methods}

\section{Field Methods}

We collected Bd water samples opportunistically from 41 known amphibian breeding sites along a longitudinal gradient focused in the western United States west of 105 degrees West, as well as a latitudinal gradient spanning the continent between 45 and 48 degrees North (Figure 1). We measured water quality (i.e. temperature, $\mathrm{pH}$, specific conductance) at 22 of the 41 sites, herein WQ sites. At one site, Barnes Road, in addition to temperature, $\mathrm{pH}$, and specific conductance, we also measured turbidity. The sites occur in temperate ecoregions in a variety of land use settings ranging from urban/suburban to wilderness, and at elevations ranging from near sea level to nearly $2000 \mathrm{~m}$. At each site, three replicate Bd water samples were collected. Samples were collected from shallow water, less than 1 meter in depth, typically between 5 and $20 \mathrm{~cm}$ below the water surface. We collected samples one time from each site between the months of May and September, and between the years 2007 and 2010. The timing of sampling was not 
even across months, the majority of sites, $63 \%$, were sampled in June and July. One site, Barnes Road had multiple repeat visits between 2007 and 2011 to record temporal variation that may be occurring.

Samples were collected using the protocol described in Kirshtein et al. (2007), with modifications to improve DNA recovery and sampling efficiency. A general overview is as follows: using a sterile $60 \mathrm{~mL}$ syringe rinsed 3 times with native water, we filtered water drawn from below the surface through a Sterivex 0.22 uM capsule filter (Fisher \# SVGP 010, luer-loc with male end) until the filter was nearly clogged. The volume was recorded and sample was flushed with $50 \mathrm{ml}$ of DNAase/RNAse-free $0.01 \mathrm{Mol}$ Phosphate Buffered Saline (PBS, SigmaAldrich \# P5368) using a new sterile syringe to remove excess dissolved organic carbon, then dried by removing the filter, drawing air into the syringe, reattaching the filter and pushing air through the filter 1-2 times. One end of the capsule filter was sealed with Hemato-Seal clay (Fisher \# 23-550-112, we found other types dried and cracked in the field, compromising the seal), injected the filter with $0.9 \mathrm{ml}$ cell lysis buffer solution (Fisher \# FP2301320), then sealed it with a luer-loc cap (Cole Parmer \# EW-45503-56). Each sample was placed in an individual Whirl-pak bag (Fisher \# 01-81205A) and kept cool until returning from the field. Samples were refrigerated until DNA extraction occurred, typically less than three months from sample collection. The lysis manufacturer suggests samples will remain stable at room temperature for up to 18 months, however we have not tested this for Bd samples. Temperature, $\mathrm{pH}$, specific conductance, and turbidity were measured with a single YSI data sonde with multiple probes, which was calibrated using standardized USGS protocols to ensure quality control and assurance of these data. PRISM (Parameter-elevation Regressions on Independent Slopes Model) climate 
mapping system were used in models that included landscape level weather data. Bd data are archived in the USGS Western Ecological Research Center Multitaxa Database and water quality data are archived in the USGS National Water Information System.

\section{Laboratory Methods}

DNA was extracted from the cell lysis solution using the Gentra Puregene Tissue Kit. We added proteinase $K(0.1 \mathrm{mg} \mathrm{ml-1)}$ directly to the filter by opening the luer-loc cap, injected the solution and resealed the capsule then placed it in a sterile $50 \mathrm{ml}$ tube, and incubated it at $55^{\circ} \mathrm{C}$ for $60 \mathrm{~min}$ in a continually rotating rack inside the incubator. We did this to ensure the filter was completely bathed in the lysis/proteinase K solution. Following this step, we drew the solution out of the filter with a sterile syringe, and continued the extraction following the manufacturer's protocol. Quantitative PCR assays were conducted using the Qiagen QuantiTect SYBR Green PCR kit. We ran each sample in duplicate and considered it positive if both wells returned a positive result. If only one well was positive, we considered the result positive only after we re-ran duplicate samples and at least one well was positive again. To quantify the $\mathrm{Bd}$ genomic equivalents, we calculated a conversion factor from a dilution series of known zoospore numbers, i.e. 169 , which is within the range of 60 to 220 for rRNA fungal gene locus copy numbers (Simon et al. 2005). If the result yielded less than 10 genomic equivalents, we considered it a qualitative positive but not a quantitative positive (Kirshtein et al. 2007). We considered a site positive if at least one of the three replicate filter samples returned a positive qPCR result.

\section{Statistical Methods}


Data were summarized using the base packages available in $\mathrm{R} 2.14 .0$. At the intensively monitored site, Barnes Road, we summarized the data using descriptive statistics and tested for a correlation between Bd detection and water quality using Pearson's correlation coefficient. To include this site in our occupancy analysis, we randomly selected one sampling event that occurred within the sampling period of the other sites, e.g. between May and September, and between the years 2007 and 2010 .

To examine the relationships between Bd occupancy of amphibian habitats and our covariates of interest, we used the software Presence 4.4 (available online). Occupancy models require multiple observations at each site to estimate $\mathrm{p}$. We treated each water sample as an observation in this context and had 3 samples per site. We used a single season occupancy model to simultaneously estimate the site level probability of Bd occurrence in amphibian habitats $(\Psi)$ while taking the observation level probability of detecting Bd in amphibian habitats when it is present (p) into account and relating both parameters to hypothesized covariates. We conducted two analyses, one that included all sites $(n=41)$, and another for the subset of WQ sites $(n=22)$. For all sites, we investigated nine covariates hypothesized to relate to the probability of occurrence $(\Psi)$ and two covariates hypothesized to relate to detection probability (p) in amphibian habitats, i.e. $\mathrm{p}$ as a function of volume and $\mathrm{p}$ is constant across surveys (Table 1). In the subset of WQ sites, we investigated three additional water quality covariates hypothesized to relate to the probability of occurrence (Table 1). Continuous covariates were standardized to $\mathrm{X}$ $\mathrm{bar}=0$ and standard deviation $=1$. We included a maximum of three covariates for $\Psi$ to avoid over-fitting, and ran models in all possible combinations of the nine hypothesized covariates to fit different hypothesized models for $\Psi$. We evaluated the strength of evidence for each of our 
hypotheses based on Akaike's Information Criteria (AICc) and the resulting Akaike's weights. If the delta AICc was less than 2, we considered this little evidence to support a difference between the models. When the delta AICc was above 2 and less than 5 we considered this as some evidence to support a difference between the models, and if the delta AICc was above 5 and less than 8 this was considered good evidence to support a difference between the models. If the delta AICc was above 8 , we considered this strong evidence to support a difference between the models. Using the Betas from the top performing model for all 41 sites, we also estimated the detection probability given the number of samples collected and the volume of the water filtered per sample.

\section{Results}

\section{Intensively Monitored Site (Barnes Road, Oregon)}

We detected $B d$ at least once in all months sampled, although not necessarily in every month in a given year, e.g. Bd was detected in the month of December 2 of 4 years we sampled (Figure 2). As we predicted, $B d$ zoospore density was highest in the spring months and lowest in the summer months. Although we predicted Bd density would be low in the winter months, we observed a second peak in December in 2 of the 4 years we sampled (2007 and 2008). April and May had the highest mean zoospore densities per $\mathrm{L}$ and the mean density was lowest in the summer, autumn and winter months (Figure 2). Our final sampling event in March 2011 recovered 3,159,289 zoospores/L from one filter (omitted from data summary for ease of plotting), approximately four orders of magnitude greater than any previous observation. $B d$ detection and density was not correlated with any of the water quality variables we measured. 


\section{All Amphibian Habitats}

We detected $B d$ at least once in all months sampled, April through September (Figure 3, mean: 15.19 zoospores/L; median: 0 zoospores/L; range: 0-344 zoospores/L.). At these sites, the mean zoospore densities were highest in April and August, which was contrary to our prediction (Figure 3). We observed low Bd densities at most sites, however two Nevada sites sampled in May were more than 50 times the densities we observed at other sites sampled in May $(2,109$ and 4,924 zoospores/L, omitted from data summary for ease of plotting). These two sites were drying rapidly and were occupied by American Bullfrogs. A concurrent mass dieoff event was observed at these sites during sample collection. We detected $B d$ in $46.67 \%$ of amphibian habitats sampled (19 of 41 sites) but estimated $B d$ occupancy at $61.46 \%$ of all sites $(\mathrm{SE}=0.1079, \mathrm{CI}=39.49-79.57)$ based on the top ranked model. Global models were the best fit for $B d$ occupancy and detection probability, therefore, we did not find sufficient evidence of a difference in model performance to allow prediction based on the covariates we selected to model (Table 2).

We determined that when $\mathrm{Bd}$ is present at a site, the probability of detecting $\mathrm{Bd}$ is $90 \%$ when 4 samples are collected. There was no difference in the detection probability and the number of samples between low and high volumes of water sampled (60ml versus $600 \mathrm{ml})$.

\section{Water Quality Sites}

At the subset of sites where water quality was also collected, Bd density was highest in April

(Figure 4). We detected $B d$ in $45 \%$ of amphibian habitats sampled (10 of 22 sites) but estimated $B d$ occupancy at $50.27 \%(\mathrm{SE}=0.1235, \mathrm{CI}=0.3330-0.7380)$ of the subset of sites where 
water quality data were also collected. Latitude appeared in the top 13 models with various combinations of julian day and elevation as covariates of $\mathrm{psi}$, and $\mathrm{pH}$ and volume as covariates of $\mathrm{p}$. The delta AICc of all of these models was less than 3, indicating little difference in model performance between them (Table 3). Given this, and the minor incremental differences between each model, it is not possible to distinguish between the effect of each individual covariate and the combined effects, therefore, we did not find substantial evidence for a difference in overall model performance with the covariates we chose.

\section{Discussion}

\section{Intensively Monitored Site (Barnes Road, Oregon)}

$\mathrm{Bd}$ appears to persist in the aquatic environment year-round. The Barnes Road site supports a diverse amphibian assemblage, including species that over winter as larvae and are year-round residents (e.g. Northwestern Salamander: Ambystoma gracile, American Bullfrog: Lithobates catesbeiana). Our observation of over 3 million zoospore genomic equivalents from a liter of water suggests that we captured a free floating colony of zoosporangia, and that Bd may be capable of growing and reproducing independent of hosts if nutrients are not limiting. Barnes Road has bullfrogs present, which means amphibians are present in the water year-round, although adult and larval density may not provide enough nutrients to sustain $\mathrm{Bd}$ through the winter months, especially if their metabolism is at its lowest of the year.

\section{All Amphibian Habitats and Water Quality Sites}

This method is a reliable way to assess the status of $\mathrm{Bd}$ in amphibian habitats when as little as 60 
$\mathrm{ml}$ of water is filtered and 4 samples are collected; however, it does not provide information on the status of $\mathrm{Bd}$ in the amphibians within these habitats. Bd densities recovered were well above the detection limit of the $\mathrm{qPCR}$, which also affirms this as a viable method for Bd detection and quantification in amphibian habitats. Sampling during the spring months resulted in the highest Bd densities.

We observed a $10 \%$ increase in occupancy estimates as we increased the number of sites which suggests that having too few sites may result in underestimating Bd occupancy in amphibian habitats. In the models with fewer sites (water quality subset), volume appeared to be an important predictor, however, when all 41 sites were included, volume was not an important predictor, again indicating the importance of sampling enough sites, as well as considering study specific objectives which may indicate sampling higher volumes of water when fewer sites are being sampled. It is likely that latitude appeared in the top performing water quality models because the water quality sites were clustered in a relatively narrow latitude range between approximately 42 and 48 degrees, and all sites covered a much broader latitudinal range which diluted the effect of latitude.

Spring peaks in Bd density may be explained be a few different phenomena deserving of further investigation. One explanation may be that upland associated amphibian species (e.g. red-legged frogs, western toads, long-toed salamanders, rough-skinned newts) that are Bd positive are arriving at to breeding sites and releasing $\mathrm{Bd}$ into the aquatic environment. Another explanation may be that the arrival of amphibians stimulates $\mathrm{Bd}$ that is living in the aquatic environment to grow, thereby increasing density. The increase in amphibian species diversity, density and 
activity, as well as changes in seasonal diel periods may all play a role in the observed increase in the spring months. Diel periods may also shed light on the observations of the density peaks observed in both April and August at water quality sites as these months have 13-14 hour daylight periods within the study area.

The relationship between water quality and $\mathrm{Bd}$ detection, and for future analyses $\mathrm{Bd}$ density, requires a finer scale than the course scale of this pilot study. The observed temperature and $\mathrm{pH}$ ranges were always within the range $\mathrm{Bd}$ can survive and grow and were often within the range for optimal growth, which provides clear evidence of why these covariates were not predictors of $\mathrm{Bd}$. The lack of an observed relationship between $\mathrm{Bd}$ detection and specific conductance and turbidity may be because these relationships are finer in scale than our measurements (e.g. specific nitrogen and phosphorous species, bio-available carbon, turbidity source and sediment loading, phytoplankton composition).

Given the evolutionary history of chytrids and their role as a role as plant decomposers coupled with the timing of winter peaks in 2007-08, we are interested in investigating whether Bd utilizes phytoplankton, specifically diatoms, as a secondary host. Future work will expand the geographic scope of this pilot study, refine the water chemistry measurements to include nitrogen and phosphorous species, total organic carbon, and characterizing the phytoplankton community over space and time. 

Tables

\begin{tabular}{|l|l|l|}
\hline Covariate abbreviation and description & $\begin{array}{l}\text { probability of } \\
\text { occurrence }(\Psi)\end{array}$ & $\begin{array}{l}\text { detection } \\
\text { probability }(p)\end{array}$ \\
\hline vol = volume of water filtered from an amphibian habitat to the nearest ml & NA & All Sites \\
\hline $\begin{array}{l}\text { temp = temperature in degrees Celsius to the nearest tenth at the location a } \\
\text { filter was collected }\end{array}$ & WQ Sites & NA \\
\hline ph $=\mathrm{pH}$ at the location a filter was collected & WQ Sites & NA \\
\hline $\begin{array}{l}\text { sp_cond = Specific conductance in microsiemens (uS), standardized to } \\
25 \mathrm{C}, \text { at the location a filter was collected }\end{array}$ & WQ Sites & NA \\
\hline lat = latitude in decimal degrees, datum WSG84 & All Sites & NA \\
\hline $\begin{array}{l}\text { long = longitude in decimal degrees, datum WGS84 } \\
\text { elev = Elevation in m to the nearest whole number }\end{array}$ & All Sites & NA \\
\hline $\begin{array}{l}\text { precip = precipitation in mm in the 24 hours prior to sampling, source } \\
\text { PRISM }\end{array}$ & All Sites & NA \\
\hline $\begin{array}{l}\text { tmin = minimum temperature in degrees C in the 24 hours prior to } \\
\text { sampling, source PRISM }\end{array}$ & All Sites \\
\hline $\begin{array}{l}\text { tmax = maximum temperature in degrees C in the 24 hours prior to } \\
\text { sampling, source PRISM }\end{array}$ & All Sites & NA \\
\hline $\begin{array}{l}\text { tran = temperature range in degrees C in the 24 hours prior to sampling, } \\
\text { source PRISM }\end{array}$ & All Sites & NA \\
\hline $\begin{array}{l}\text { dew = Dew Point or water-to-air saturation temperature in the 24 hours } \\
\text { prior to sampling, source PRISM }\end{array}$ & All Sites & NA \\
\hline \begin{tabular}{l} 
day = Day of year \\
\hline
\end{tabular} & All Sites & NA \\
\hline
\end{tabular}

Table 1. Covariates hypothesized to relate to the probability of occurrence $(\Psi)$ or detection probability $(\rho)$ of Batrachochytrium dendrobatidis $(B d)$ in amphibian habitats. $N A=$ the covariate was not used. All sites = all sites that were sampled for Bd. WQ Sites = a subset from all sites where water quality was also measured. 


\begin{tabular}{|c|c|c|c|c|c|c|}
\hline Model & $\mathrm{AIC}$ & deltaAIC & $\begin{array}{l}\text { AIC } \\
\text { wgt }\end{array}$ & $\begin{array}{l}\text { Model } \\
\text { Likelihood }\end{array}$ & $\begin{array}{l}\# \\
\text { Parameters }\end{array}$ & $-2 *$ LogLike \\
\hline psi(all),p(.) & 136.53 & 0 & 0.4181 & 1 & 12 & 112.53 \\
\hline psi(all),p(vol) & 138.21 & 1.68 & 0.1805 & 0.4317 & 13 & 112.21 \\
\hline psi(elev),p(.) & 139.89 & 3.36 & 0.0779 & 0.1864 & 3 & 133.89 \\
\hline psi(ppt+tdmean+elev),p(.) & 141.77 & 5.24 & 0.0304 & 0.0728 & 5 & 131.77 \\
\hline psi(elev+lat),p(.) & 141.82 & 5.29 & 0.0297 & 0.071 & 4 & 133.82 \\
\hline psi(.),p(.) & 142.14 & 5.61 & 0.0253 & 0.0605 & 2 & 138.14 \\
\hline psi(lat $), p()$. & 142.32 & 5.79 & 0.0231 & 0.0553 & 3 & 136.32 \\
\hline psi(lat+long+elev),p(.) & 142.63 & 6.1 & 0.0198 & 0.0474 & 5 & 132.63 \\
\hline psi(ppt+tmax+elev),p(.) & 142.94 & 6.41 & 0.017 & 0.0406 & 5 & 132.94 \\
\hline psi(ppt+trange+elev),p(.) & 143.19 & 6.66 & 0.015 & 0.0358 & 5 & 133.19 \\
\hline psi(year),p(.) & 143.41 & 6.88 & 0.0134 & 0.0321 & 3 & 137.41 \\
\hline psi(trange),p(.) & 143.69 & 7.16 & 0.0117 & 0.0279 & 3 & 137.69 \\
\hline 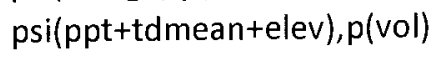 & 143.77 & 7.24 & 0.0112 & 0.0268 & 6 & 131.77 \\
\hline psi(elev+lat),p(vol) & 143.79 & 7.26 & 0.0111 & 0.0265 & 5 & 133.79 \\
\hline psi(long),p(.) & 143.91 & 7.38 & 0.0104 & 0.025 & 3 & 137.91 \\
\hline psi(julian),p(.) & 144.06 & 7.53 & 0.0097 & 0.0232 & 3 & 138.06 \\
\hline psi(tdmean),p(.) & 144.09 & 7.56 & 0.0095 & 0.0228 & 3 & 138.09 \\
\hline psi(tmin),p(.) & 144.1 & 7.57 & 0.0095 & 0.0227 & 3 & 138.1 \\
\hline psi(ppt),p(.) & 144.11 & 7.58 & 0.0094 & 0.0226 & 3 & 138.11 \\
\hline psi(tmax),p(.) & 144.13 & 7.6 & 0.0094 & 0.0224 & 3 & 138.13 \\
\hline psi(.),p(vol) & 144.13 & 7.6 & 0.0094 & 0.0224 & 3 & 138.13 \\
\hline psi(lat+long+elev),p(vol) & 144.62 & 8.09 & 0.0073 & 0.0175 & 6 & 132.62 \\
\hline psi(ppt+tmin+elev),p(vol) & 145.14 & 8.61 & 0.0056 & 0.0135 & 6 & 133.14 \\
\hline psi(ppt+trange+elev),p(vol) & 145.17 & 8.64 & 0.0056 & 0.0133 & 6 & 133.17 \\
\hline psi(year+julian),p(.) & 145.21 & 8.68 & 0.0055 & 0.013 & 4 & 137.21 \\
\hline psi(ppt+trange),p(.) & 145.43 & 8.9 & 0.0049 & 0.0117 & 4 & 137.43 \\
\hline psi(ppt+tmin),p(.) & 146.08 & 9.55 & 0.0035 & 0.0084 & 4 & 138.08 \\
\hline psi(ppt+tdmean),p(.) & 146.08 & 9.55 & 0.0035 & 0.0084 & 4 & 138.08 \\
\hline $\mathrm{psi}(\mathrm{ppt}+\mathrm{tmax}), \mathrm{p}()$. & 146.11 & 9.58 & 0.0035 & 0.0083 & 4 & 138.11 \\
\hline psi(.),p(id) & 146.74 & 10.21 & 0.0025 & 0.0061 & 5 & 136.74 \\
\hline psi(year+julian),p(vol) & 147.15 & 10.62 & 0.0021 & 0.0049 & 5 & 137.15 \\
\hline psi(ppt+trange),p(vol) & 147.39 & 10.86 & 0.0018 & 0.0044 & 5 & 137.39 \\
\hline psi(ppt+tdmean),p(vol) & 148.06 & 11.53 & 0.0013 & 0.0031 & 5 & 138.06 \\
\hline psi(ppt+tmax),p(vol) & 148.09 & 11.56 & 0.0013 & 0.0031 & 5 & 138.09 \\
\hline
\end{tabular}




\begin{tabular}{|c|c|c|c|c|c|c|}
\hline Model & AIC & deltaAlC & AIC wgt & Likelihood & Parameters & $-2^{*}$ LogLike \\
\hline $\mathrm{psi}($ lat $), \mathrm{p}(\mathrm{ph})$ & 67.4 & 0 & 0.1089 & 1 & 4 & 59.4 \\
\hline psi(lat),p(vol+ph) & 67.8 & 0.4 & 0.0892 & 0.8187 & 5 & 57.8 \\
\hline psi(lat),p(.) & 67.84 & 0.44 & 0.0874 & 0.8025 & 3 & 61.84 \\
\hline psi(lat),p(vol) & 68.23 & 0.83 & 0.0719 & 0.6603 & 4 & 60.23 \\
\hline psi(lat+julian),p(vol+ph) & 68.61 & 1.21 & 0.0595 & 0.5461 & 6 & 56.61 \\
\hline psi(lat+julian),p(ph) & 68.84 & 1.44 & 0.053 & 0.4868 & 5 & 58.84 \\
\hline psi(lat+julian),p(.) & 69.13 & 1.73 & 0.0459 & 0.4211 & 4 & 61.13 \\
\hline psi(lat+julian),p(vol) & 69.36 & 1.96 & 0.0409 & 0.3753 & 5 & 59.36 \\
\hline psi(lat+elev),p(ph) & 69.39 & 1.99 & 0.0403 & 0.3697 & 5 & 59.39 \\
\hline psi(lat+elev),p(vol+ph) & 69.71 & 2.31 & 0.0343 & 0.3151 & 6 & 57.71 \\
\hline psi(lat+elev),p(.) & 69.78 & 2.38 & 0.0331 & 0.3042 & 4 & 61.78 \\
\hline psi(lat+julian+elev),p(3) & 70.05 & 2.65 & 0.0289 & 0.2658 & 6 & 58.05 \\
\hline psi(lat+elev),p(vol) & 70.13 & 2.73 & 0.0278 & 0.2554 & 5 & 60.13 \\
\hline psi(.),p(vol+ph) & 70.18 & 2.78 & 0.0271 & 0.2491 & 4 & 62.18 \\
\hline psi(elev),p(ph) & 70.76 & 3.36 & 0.0203 & 0.1864 & 4 & 62.76 \\
\hline psi(elev),p(vol+ph) & 70.86 & 3.46 & 0.0193 & 0.1773 & 5 & 60.86 \\
\hline psi(lat+julian+elev), p(.) & 71.02 & 3.62 & 0.0178 & 0.1637 & 5 & 61.02 \\
\hline psi(all),p(.) & 71.06 & 3.66 & 0.0175 & 0.1604 & 6 & 59.06 \\
\hline psi(all),p(all) & 71.07 & 3.67 & 0.0174 & 0.1596 & 10 & 51.07 \\
\hline psi(lat+julian+elev),p(1) & 71.25 & 3.85 & 0.0159 & 0.1459 & 6 & 59.25 \\
\hline psi(julian+elev),p(3) & 71.54 & 4.14 & 0.0137 & 0.1262 & 5 & 61.54 \\
\hline psi(.),p(ph) & 71.64 & 4.24 & 0.0131 & 0.12 & 3 & 65.64 \\
\hline psi(elev),p(.) & 71.86 & 4.46 & 0.0117 & 0.1075 & 3 & 65.86 \\
\hline psi(julian+elev),p(.) & 71.94 & 4.54 & 0.0113 & 0.1033 & 4 & 63.94 \\
\hline psi(elev),p(vol) & 71.94 & 4.54 & 0.0113 & 0.1033 & 4 & 63.94 \\
\hline psi(julian),p(vol+ph) & 71.98 & 4.58 & 0.011 & 0.1013 & 5 & 61.98 \\
\hline psi(julian+elev),p(1) & 72.09 & 4.69 & 0.0104 & 0.0958 & 5 & 62.09 \\
\hline psi(.),p(vol) & 72.4 & 5 & 0.0089 & 0.0821 & 3 & 66.4 \\
\hline psi(lat+julian_elev),p(4) & 72.56 & 5.16 & 0.0083 & 0.0758 & 6 & 60.56 \\
\hline psi(lat+julian+elev),p(2) & 72.73 & 5.33 & 0.0076 & 0.0696 & 6 & 60.73 \\
\hline psi(.),p(.) & 73.09 & 5.69 & 0.0063 & 0.0581 & 2 & 69.09 \\
\hline psi(julian+elev),p(2) & 73.55 & 6.15 & 0.005 & 0.0462 & 5 & 63.55 \\
\hline psi(julian),p(ph) & 73.59 & 6.19 & 0.0049 & 0.0453 & 4 & 65.59 \\
\hline psi(julian+elev),p(4) & 73.78 & 6.38 & 0.0045 & 0.0412 & 5 & 63.78 \\
\hline psi(julian),p(vol) & 74.08 & 6.68 & 0.0039 & 0.0354 & 4 & 66.08 \\
\hline psi(.),p(temp) & 74.65 & 7.25 & 0.0029 & 0.0266 & 3 & 68.65 \\
\hline psi(julian),p(.) & 74.9 & 7.5 & 0.0026 & 0.0235 & 3 & 68.9 \\
\hline psi(.),p(spcond) & 74.97 & 7.57 & 0.0025 & 0.0227 & 3 & 68.97 \\
\hline psi(long),p(.) & 74.98 & 7.58 & 0.0025 & 0.0226 & 3 & 68.98 \\
\hline psi(.),p(all) & 76.1 & 8.7 & 0.0014 & 0.0129 & 7 & 62.1 \\
\hline
\end{tabular}

Table 3. Model selection statistics for a priori models relating occupancy (psi) and probability of detection (p) of Batrachochytrium dendrobatidis from 22 amphibian habitats with water quality and geographic covariates in North America. 


\section{Figure Legends}

Figure 1. Sampling locations, with results of water sampling

Figure 2. $B d$ zoospore density from 41 amphibian survey sites

Figure 3. Bd zoospore density from a subset of 22 amphibian habitats with WQ data

Figure 4. Bd zoospore density, Barnes Road, Oregon July 2007-March 2011

Figure 5. Temperature at each sampling location from Barnes Road, Oregon July 2007-March 2011

Figure 6. pH measured at each sampling occasion Barnes Road, Oregon July 2007-March 2011

Figure 7. Probability of detecting Bd in an amphibian habitat by sampling water from amphibian habitats $(\mathrm{vol}=60-600 \mathrm{~mL} / \mathrm{sample})$ 
Figures

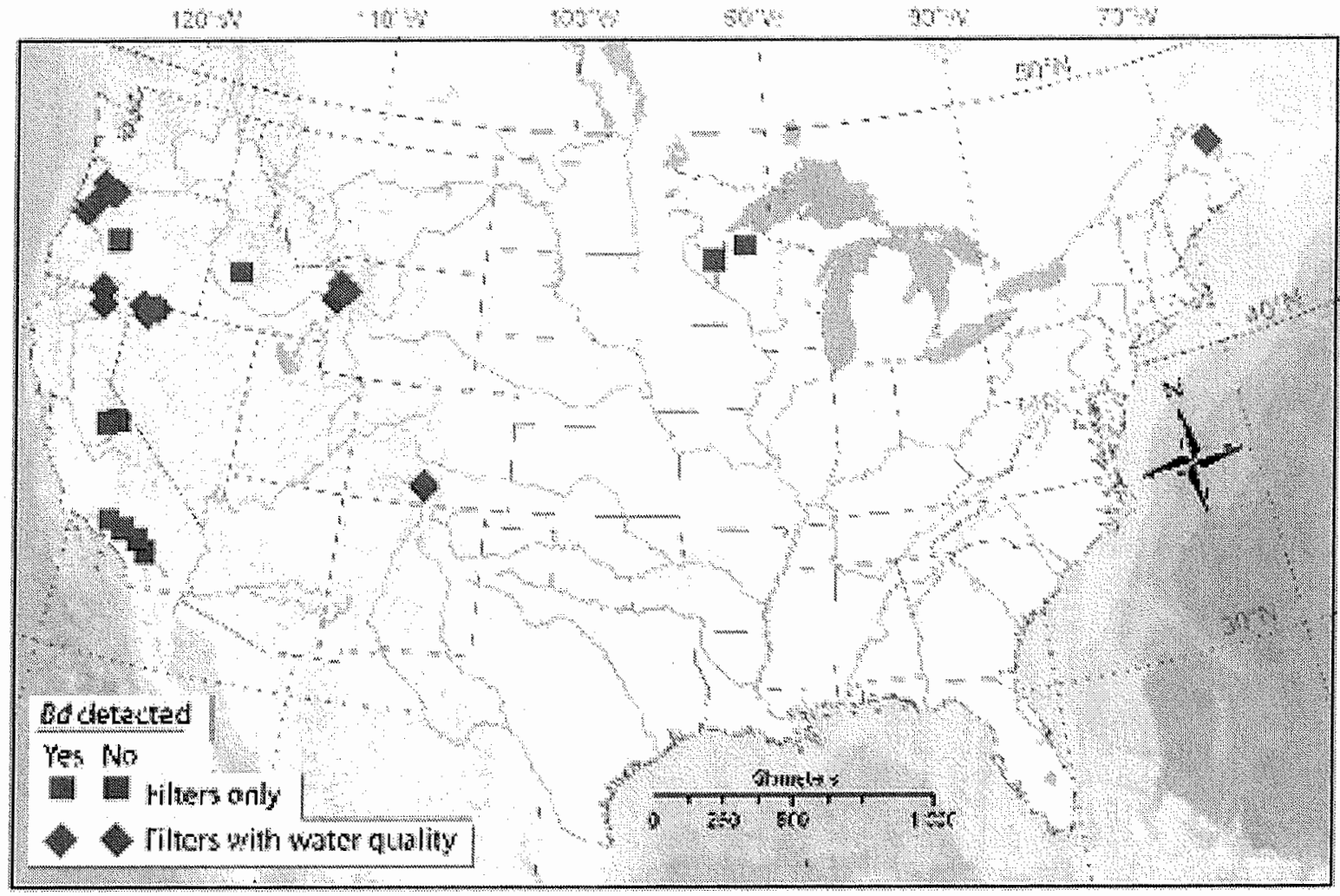




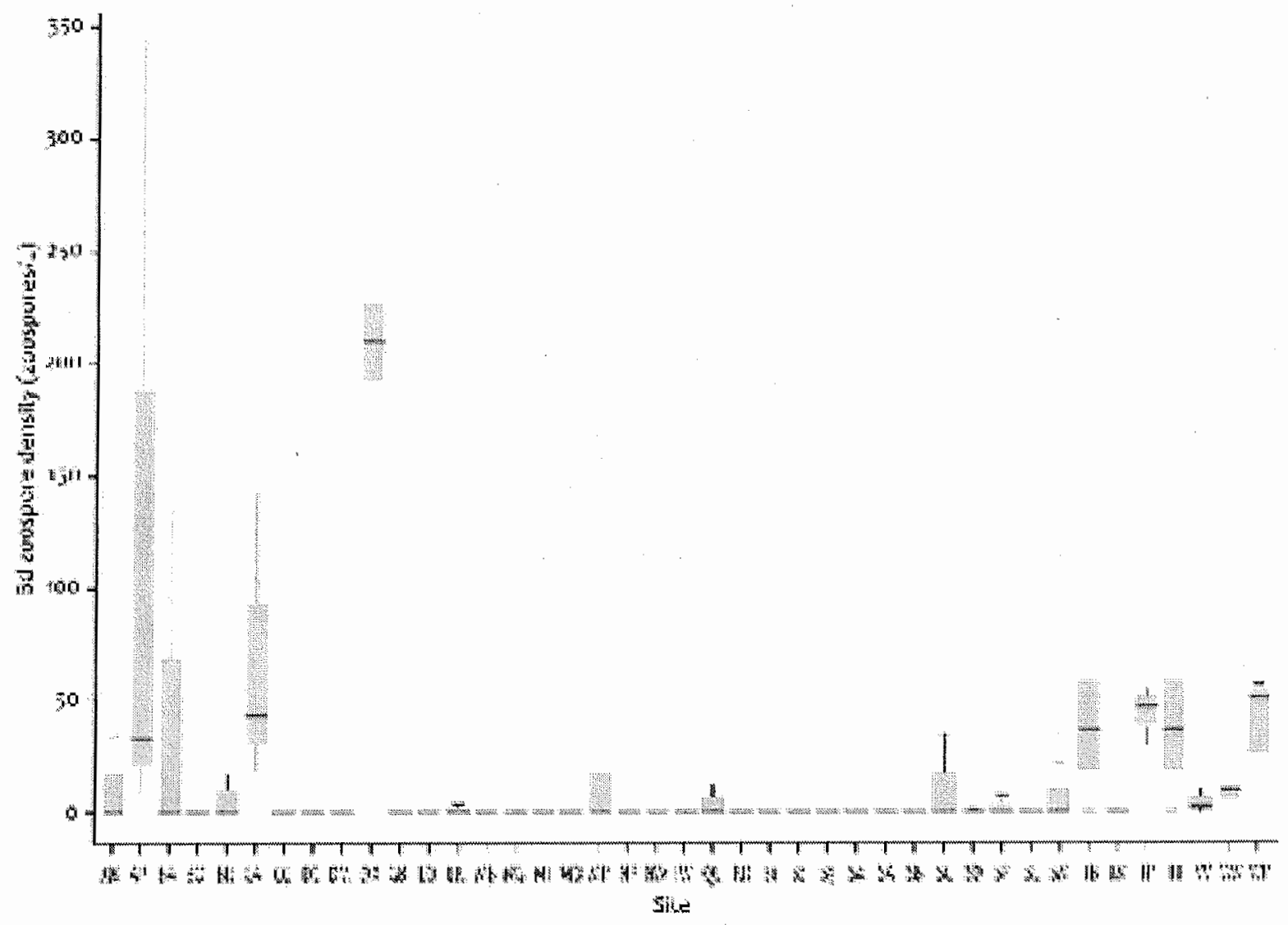




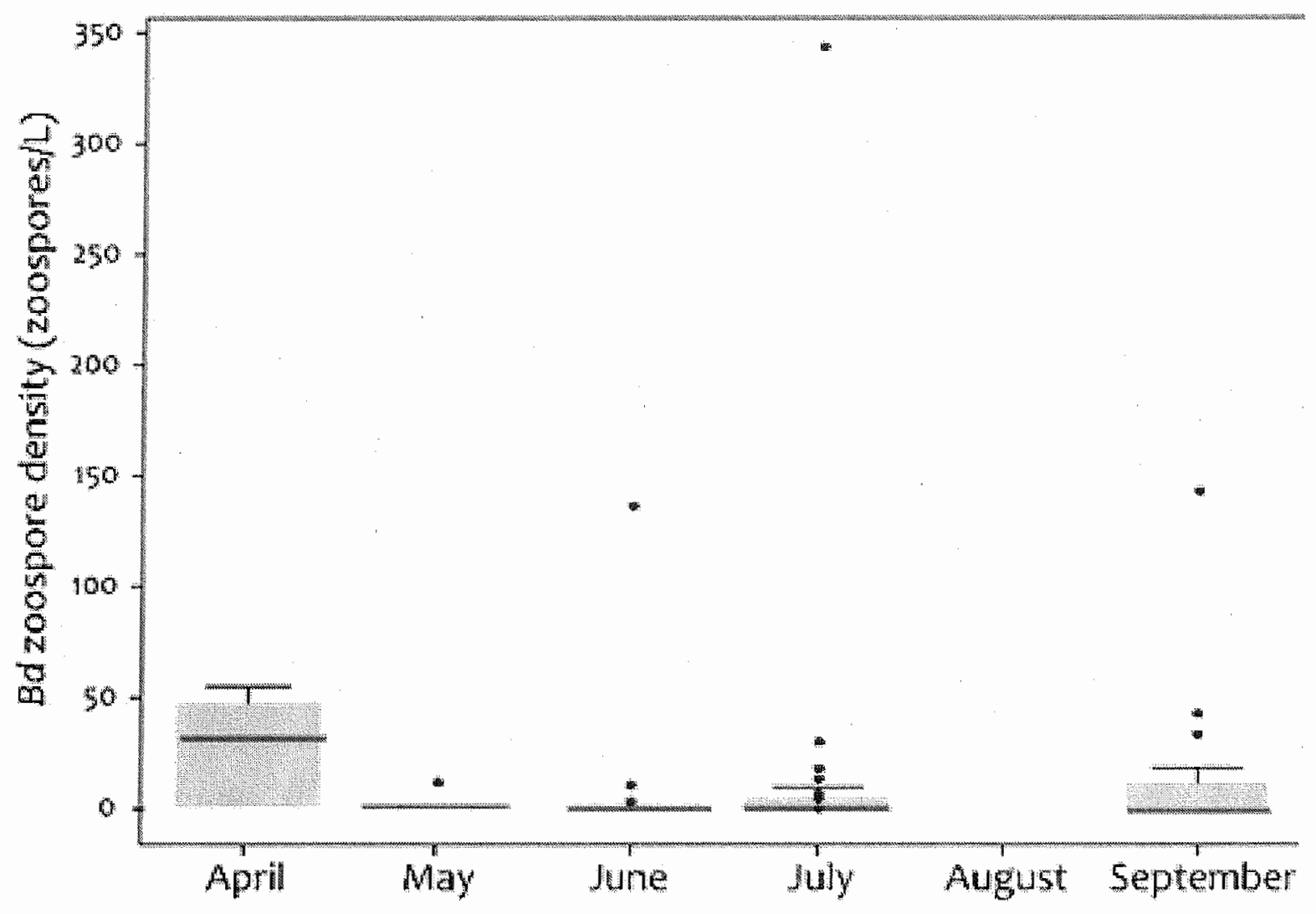




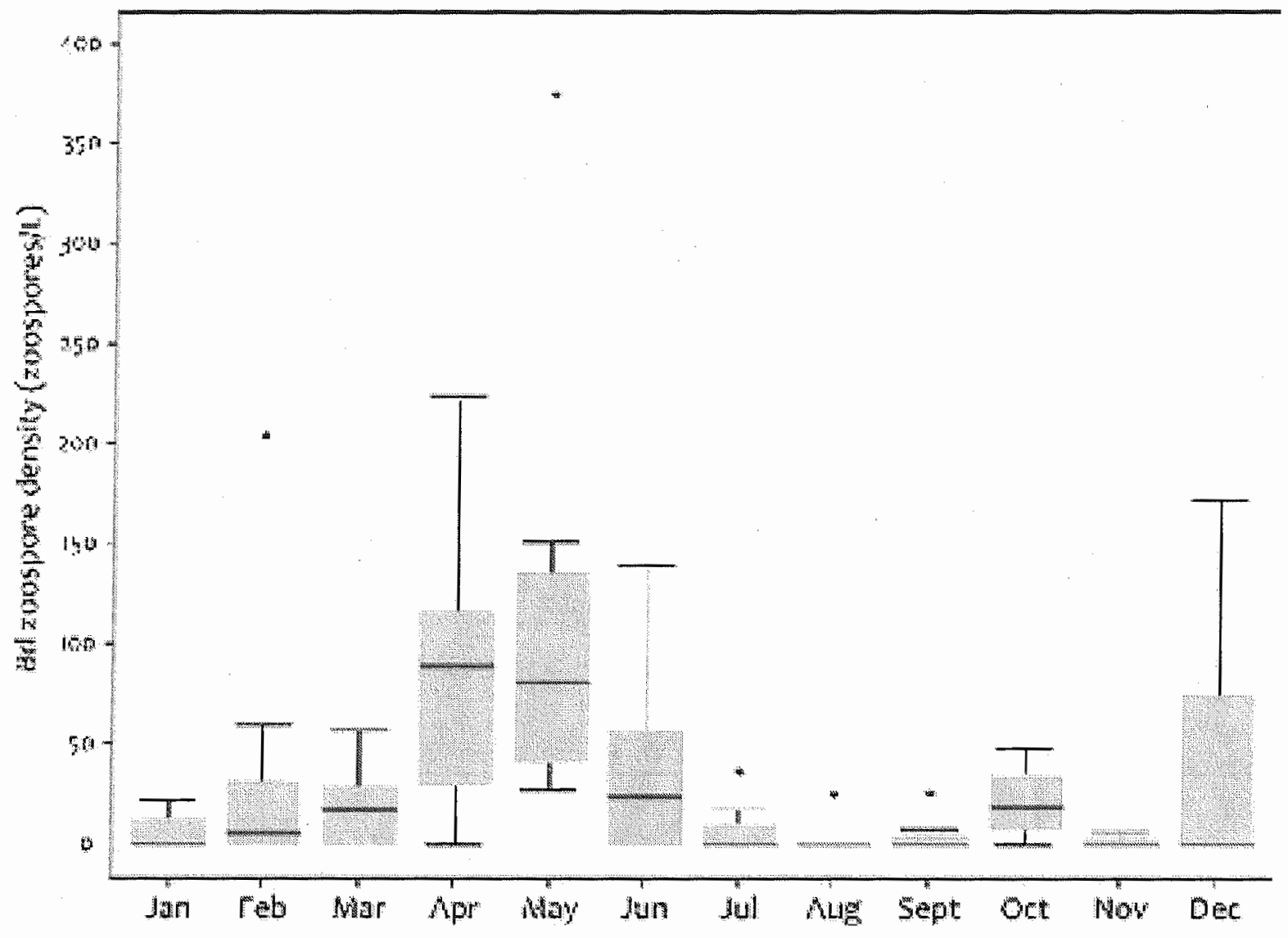




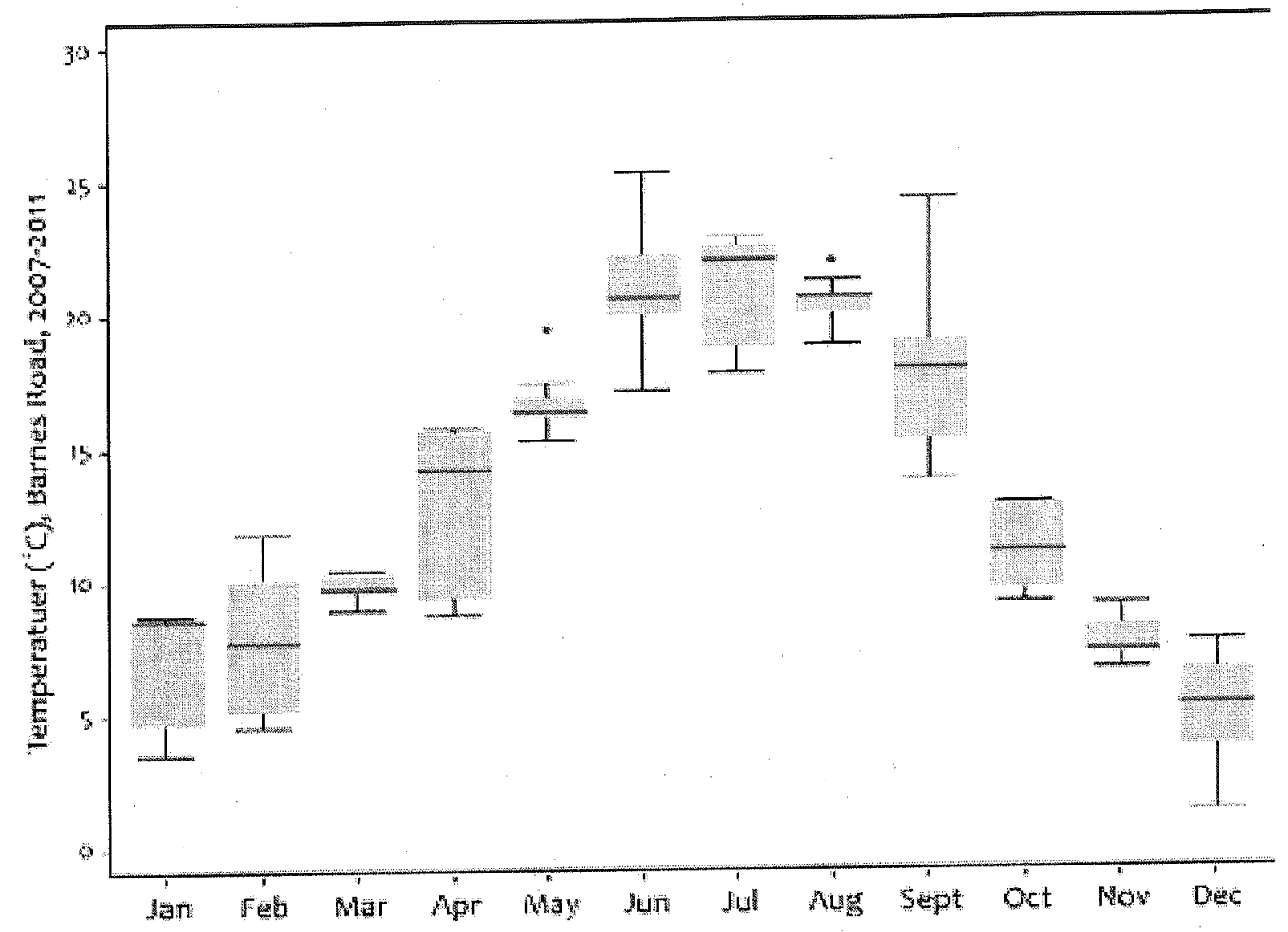



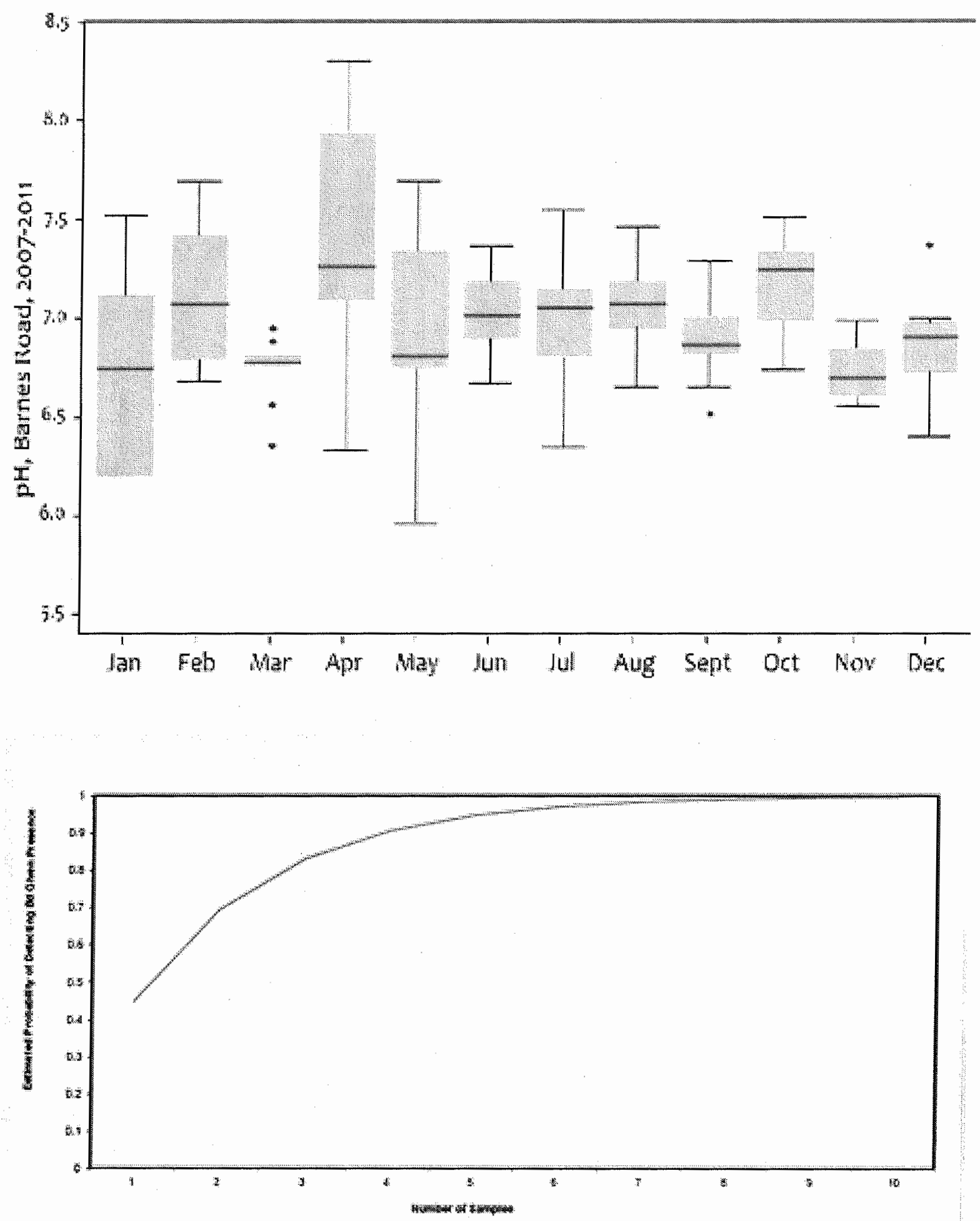
